\title{
DISTRIBUTION OF NUTRIENTS, POLYPHENOLS AND ANTIOXIDANT ACTIVITIES IN THE PILEI AND STIPES OF SOME COMMONLY CONSUMED EDIBLE MUSHROOMS IN NIGERIA
}

\author{
G. Oboh ${ }^{*}$ and S.A. Shodehinde
}

Biochemistry Department, Federal University of Technology, P.M.B. 704, Akure, Nigeria

(Received June 22, 2008; revised May 4, 2009)

\begin{abstract}
The distribution of nutrients, polyphenols and antioxidant activities between the pilei (caps) and stipes (stalks) of three commonly consumed edible mushrooms in Nigeria namely: Termitomyces robustus [pilei (TRC) and stipes (TRS)], Coprinus $\underline{s p}$ [pilei (CSC) and stipes (CSS)] and Volvariella esculenta [pilei (VEC) and stipes (VES)] were evaluated. The pilei were separated from the stipes and their proximate composition was determined. Thereafter, their antioxidant properties as typified by their total phenol content, reducing power, DPPH free radical scavenging ability and inhibition of lipid peroxidation in vitro were determined. The pilei of the mushrooms had significantly higher $(\mathrm{p}<0.05)$ protein, fat and ash content than the stipes, while the crude fibre was significantly higher $(p<0.05)$ in the stipes than the pilei. However, no significant difference $(p>0.05)$ exists between the total phenol content of the pilei [VEC $(2.1 \mathrm{mg} / \mathrm{g})$, TRC $(2.5 \mathrm{mg} / \mathrm{g})$, CSC $(2.3 \mathrm{mg} / \mathrm{g})$ ] and the stipes [VES $(2.0 \mathrm{mg} / \mathrm{g})$, TRS $(2.3 \mathrm{mg} / \mathrm{g}), \mathrm{CSS}(1.8 \mathrm{mg} / \mathrm{g})]$. Nevertheless, polyphenol extracts from the stipes had a significantly $(\mathrm{p}<0.05)$ higher free radical scavenging ability and reducing power than those from the pilei. Furthermore, the polyphenol extracts inhibited lipid peroxidation in the cow's brain homogenates in a dose dependent manner; however, no significant difference $(\mathrm{p}>0.05)$ exists in the inhibitory effect of the polyphenols at higher concentrations. Therefore, pilei of the mushrooms had more protein, ash and fat content; while there was no significant difference in the polyphenol distribution between the pilei and stipes; conversely the polyphenols from the stipes had higher antioxidant activity (except inhibition of lipid peroxidation) than that of the pilei.
\end{abstract}

KEY WORDS: Antioxidant, Mushrooms, Nutrients, Pilei, Polyphenols, Stipes

\section{INTRODUCTION}

Mushrooms are traditional food such as morel and truffles in China [1] and today, food of fungal origin is consumed all over the world in vast quantities and commercial production is part of a rapidly growing industry. Fungi are of excellent value nutritionally, and of great importance to vegetarians. Edible mushrooms have high protein content and are an excellent source of fibre, vitamins and some minerals [1]. The word 'mushroom' is thought to have been derived from the French 'mousseron' a term, which included edible mushrooms as well as poisonous varieties. Today the word refers to the edible fungi, and is generally applied to the above ground portion, the fruiting body. Those without the typical stem and cap are identified by their specific names such as morels and truffles [2]. With high content of protein, mushrooms serve as a tasty complement to sauces and soups and can substitute for fish or meat [3]. Mushrooms have long been appreciated for their flavour and texture. Now they are recognized as a nutritious food as well as an important source of biologically active compounds of medicinal value [4].

Reactive oxygen species (ROS), which include free radicals such as superoxide anion radicals, hydroxyl radicals and non free-radical species such as $\mathrm{H}_{2} \mathrm{O}_{2}$ and singlet oxygen are various forms of activated oxygen [5]. These molecules are exacerbating factors in cellular injury and aging processes. ROS cause lipid peroxidation, which is the major cause of food deterioration, affecting colour, flavour texture and nutritional value. Besides, it has been suggested that oxidative modification of low-density lipoproteins (LDLs) may play a role in the development of atherosclerosis [6]. ROS induce some oxidative damage to biomolecules like

*Corresponding author. E-mail: goboh2001@yahoo.com 
nucleic acids, proteins and carbohydrates and has been implicated in ageing, cancer and many other diseases [7].

Consumption of antioxidant rich food is a practical approach to the management of oxidative stress [8]. Consumption of vegetables and fruits as well as grains has been associated with the reduced risk of chronic diseases [9]. This has been hypothesized to be because they contain phytochemicals that combat oxidative stress in the body by helping to maintain a balance between oxidant and antioxidants. Phenolics are naturally occurring secondary metabolites from plants and have been found to be one of the most potent antioxidant plant chemicals. They are present in vegetables, fruits, leaves, nuts and seeds [10-14].

Mushrooms accumulate a variety of secondary metabolites, including phenolic compounds, polyketides, terpenes and steroids. Also, a mushroom phenolic compound has been found to be an excellent antioxidant and synergist that is not mutagenic [15]. Although a lot had been reported on the nutrient, antinutrient and mineral composition of some edible mushrooms in Nigeria [16-17], there are dearth of data with regard to the polyphenol content and antioxidant activity of pilei and stipes of commonly consumed mushrooms in Nigeria. This study therefore sought to determine the distribution of nutrients, polyphenols and antioxidant activities between the pilei (caps) and stipes (stalks) of some edible mushrooms in Nigeria namely Termitomyces robustus, Coprinus sp. and Volvariella esculenta.

\section{EXPERIMENTAL}

\section{Samples and chemicals}

Three varieties of edible mushrooms namely Termitomyces robustus, Coprinus sp. and Volvariella esculenta were purchased from a local market in Akure, Nigeria. The chemicals used were of analytical grade while the water used was glass-distilled.

\section{Sample preparation}

The mushrooms were separated into the pilei and stipes, giving rise to six samples that were subsequently washed and sun dried before analysis.

\section{Proximate composition}

The nutrient composition (ash, fat, carbohydrate and crude fibre) of the mushrooms (pilei and stipes) was determined by the AOAC method [18] and the protein content was determined using the micro-Kjeldahl method [18]. The carbohydrate was determined by difference.

\section{Extraction of polyphenol}

About $100 \mathrm{~g}$ of the sun-dried mushroom were homogenized using chilled $80 \%$ acetone (1:2, w/v) for $5 \mathrm{~min}$. The homogenates were filtered through Whatman No. 2 filter paper. The filtrate was concentrated using a rotary evaporator under vacuum at $45^{\circ} \mathrm{C}$ until approximately $90 \%$ of the filtrate had been evaporated. The extracts were frozen at $-4{ }^{\circ} \mathrm{C}$ for further analysis [19].

\section{Determination of total phenol content}

The total phenol content was determined as described by Singleton et al. [20]. Appropriate dilutions of the extract were oxidized with $2.5 \mathrm{~mL}$ of $10 \%$ Folin-ciocalteu's reagent (v/v) and neutralized by $2.0 \mathrm{~mL}$ of $7.5 \%$ sodium carbonate. The reaction mixture was incubated for 40 
Distribution of nutrients, polyphenols and antioxidant activities in the edible mushrooms 393

min at $45{ }^{\circ} \mathrm{C}$ and the absorbance was measured spectrophotometrically at $765 \mathrm{~nm}$. Tannic acid was used as standard phenol $(0.1-1.0 \mathrm{mg} / \mathrm{mL})$.

\section{Determination of reducing property}

The reducing property of the extracts was determined by assessing the ability of the extract to reduce $\mathrm{FeCl}_{3}$ solution as described by Oyaizu [21]. Appropriate dilution of the extract $(2.5 \mathrm{~mL})$ was mixed with $2.5 \mathrm{~mL} 200 \mathrm{mM}$ sodium phosphate buffer (pH 6.6) and $2.5 \mathrm{~mL} 1 \%$ potassium ferricyanide. The mixture was incubated at $50{ }^{\circ} \mathrm{C}$ for 20 min and then $2.5 \mathrm{~mL} 10 \%$ trichloroacetic acid was added. This mixture was centrifuged at $650 \mathrm{rpm}$ for $10 \mathrm{~min}$. Five millilitre of the supernatant was mixed with an equal volume of water and $1 \mathrm{~mL}$ of $0.1 \%$ ferric chloride. The absorbance was measured at $700 \mathrm{~nm}$.

DPPH free radical scavenging ability

The free radical scavenging ability of the extracts against DPPH (1,1-diphenyl-2-picrylhydrazyl) free radical was evaluated as described by Gyamfi et al. [22]. Briefly, appropriate dilution of the extracts $(1 \mathrm{~mL})$ was mixed with $1 \mathrm{~mL}, 0.4 \mathrm{mM}$ methanolic solution containing DPPH radicals, the mixture was left in the dark for $30 \mathrm{~min}$ and the absorbance was taken at $516 \mathrm{~nm}$. The DPPH free radical scavenging ability was subsequently calculated.

\section{Lipid peroxidation and thiobarbibutric acid reactions}

The lipid peroxidation assay was carried out as described by Ohkawa et al. [23]. S1 fraction $(100 \mu \mathrm{L})$ of cow's brain homogenates prepared in our laboratory in $150 \mathrm{mM} \mathrm{NaCl}$ solution $(1: 10 \mathrm{w} / \mathrm{v})$ was mixed with a reaction mixture containing $30 \mu \mathrm{L}$ of $0.1 \mathrm{M}$ Tris- $\mathrm{HCl}$ buffer $(\mathrm{pH}$ 7.4) and polyphenol extract solution $(0-100 \mu \mathrm{L})$. The volume was made up to $300 \mu \mathrm{L}$ with distilled water before incubation at $37{ }^{\circ} \mathrm{C}$ for $1 \mathrm{~h}$. The colour reaction was developed by adding $300 \mu \mathrm{L} 8.1 \%$ SDS to the reaction mixture containing S1, this was subsequently followed by the addition of $600 \mu \mathrm{L}$ of acetic acid/ $\mathrm{HCl}(\mathrm{pH} 3.4)$ and $600 \mu \mathrm{L} 0.8 \%$ TBA (thiobarbituric acid). This mixture was incubated at $100{ }^{\circ} \mathrm{C}$ for $1 \mathrm{~h}$. The thiobarbituric acid reactive species (TBARS) produced were measured at $532 \mathrm{~nm}$.

Analysis of data

The results of the three replicate analyses were pooled and expressed as mean \pm standard error (S.E.). A one-way analysis of variance (ANOVA) and the least significance difference (LSD) were carried out [24]. Significance was accepted at $\mathrm{p} \leq 0.05$.

\section{RESULTS AND DISCUSSION}

The results of the proximate composition of the pilei and stipes of the three edible wild mushrooms from Nigeria are presented in Table 1. The results revealed that the protein content of both the pilei and stipes of the mushrooms are generally high. The protein content ranged from $24.2 \%$ (Volvariella esculenta stipe) to $29.6 \%$ (Coprinus $s p$. pilei). However, the protein content of the mushrooms was higher than that of some edible mushrooms from Mexico namely Amanita rubescens, Boletus frostii, Lactarius indigo and Ramaria flava [25]. Conversely, the protein content of the mushrooms were lower than that of Termitomyces mammiformis while it is within the same range with that of Lactarius triviralis, Russula vesca and Lentinus tigrinus which are edible wild mushrooms in Nigeria [26]. Furthermore, the protein content of the pilei 
[24.4\% (Volvariella esculenta) - $29.6 \%$ (Coprinus sp.)] were significantly higher $(\mathrm{p}<0.05)$ than that of stipes [23.2\% (Volvariella esculenta) - $25.1 \%$ (Coprinus sp.)]. Therefore, the pilei of the mushrooms could be a better dietary source of protein; however, the pilei and stipes of Corpinus sp. had the highest protein content.

Table 1. Distribution of proximate composition in some edible wild mushrooms (g $100 \mathrm{~g}^{-1}$ dry weight).

\begin{tabular}{|l|c|c|c|c|c|}
\hline Sample & Protein & Ash & Fat & Crude fibre & Carbohydrate \\
\hline Termitomyces robustus & & & & & \\
\hline Pilei & $28.6 \pm 0.4^{\mathrm{a}}$ & $21.4 \pm 0.2^{\mathrm{b}}$ & $12.5 \pm 0.2^{\mathrm{a}}$ & $5.2 \pm 0.6^{\mathrm{e}}$ & $32.3 \pm 0.5^{\mathrm{c}}$ \\
\hline Stipes & $24.8 \pm 0.5^{\mathrm{b}}$ & $14.2 \pm 0.2^{\mathrm{e}}$ & $11.1 \pm 0.3^{\mathrm{b}}$ & $18.2 \pm 0.3^{\mathrm{a}}$ & $31.7 \pm 0.3^{\mathrm{c}}$ \\
\hline Coprinus sp. & & & & & \\
\hline Pilei & $29.6 \pm 0.5^{\mathrm{a}}$ & $17.5 \pm 0.4^{\mathrm{d}}$ & $12.6 \pm 0.1^{\mathrm{a}}$ & $4.3 \pm 0.5^{\mathrm{e}}$ & $36.0 \pm 0.2^{\mathrm{b}}$ \\
\hline Stipes & $25.1 \pm 0.4^{\mathrm{b}}$ & $12.3 \pm 0.2^{\mathrm{f}}$ & $10.5 \pm 0.3^{\mathrm{bc}}$ & $7.0 \pm 0.3^{\mathrm{d}}$ & $45.1 \pm 0.3^{\mathrm{a}}$ \\
\hline Volvariella esculenta & & & & & \\
\hline Pilei & $24.4 \pm 0.5^{\mathrm{b}}$ & $31.7 \pm 0.5^{\mathrm{a}}$ & $10.2 \pm 0.1^{\mathrm{c}}$ & $10.1 \pm 0.2^{\mathrm{c}}$ & $23.6 \pm 0.3^{\mathrm{d}}$ \\
\hline Stipes & $23.2 \pm 0.2^{\mathrm{c}}$ & $19.6 \pm 0.3^{\mathrm{c}}$ & $9.0 \pm 0.2^{\mathrm{d}}$ & $11.2 \pm 0.1^{\mathrm{b}}$ & $37.0 \pm 1.0^{\mathrm{b}}$ \\
\hline
\end{tabular}

Values represent means of triplicate readings. Values with the same superscript along the column are not significantly different. $\mathrm{n}=3$.

Likewise, the pilei contains significantly higher $(\mathrm{p}<0.05)$ ash $[17.5 \%$ (Corpinus sp. $)-31.7$ $\%$ (Volviriella esculenta)] and fat [10.2\% (Volvariella esculenta) - $12.6 \%$ (Corpinus sp.)] content than the stipes \{ash [12.3\% (Corpinus sp.) - $19.6 \%$ (Volvariella esculenta)] and fat [9.0\% (Volvariella esculenta) - $11.1 \%$ (Termitomyces robustus)]\}. However, both the pilei and stipe of Volvariella esculenta had the highest ash content, while Termitomyces robustus (stipes + pilei) contains the highest fat content. The fat and ash content of the mushrooms were higher than that of Termitomyces mammiformis, Lactarius triviralis, Russula vesca and Lentinus tigrinus, which are also edible wild mushrooms in Nigeria [26]. However, the stipes [7.0\% (Coprinus spp) - $18.2 \%$ (Termitomyces robustus)] of the mushrooms had a significantly higher $(\mathrm{p}<0.05)$ crude fibre than the pilei [4.3\% (Corpinus sp.) - $10.1 \%$ (Volvariella esculenta)]. Likewise, the carbohydrate content of the stipes were significantly higher $(\mathrm{p}<0.05)$ than that of the pilei except in Termitomyces robustus where there was no significant difference $(p>0.05)$ between them. The crude fibre content compared well with the value reported for Termitomyces mammiformis, Lactarius triviralis, Russula vesca and Lentinus tigrinus, which are also edible wild mushrooms in Nigeria [26], but the carbohydrate content was below those of the edible wild mushrooms reported by same authors [26].

The polyphenols distribution between the pilei and stipes of the mushrooms under study are presented in Figure 1. The results revealed that there was no significant $(\mathrm{p}>0.05)$ difference between the polyphenol content of the stipes [VES $(2.0 \mathrm{mg} / \mathrm{g})$, TRS $(2.3 \mathrm{mg} / \mathrm{g})$, CSS $(1.8 \mathrm{mg} / \mathrm{g})$ ] and pilei [VEC $(2.1 \mathrm{mg} / \mathrm{g})$, TRC $(2.5 \mathrm{mg} / \mathrm{g})$, CSC $(2.3 \mathrm{mg} / \mathrm{g})]$. The phenol contents of the mushrooms are within the same range as that of some commonly consumed green leafy vegetables in Nigeria [16-17]. Many recent reports have shown that there is a direct relationship between the total phenol content and the antioxidant activity in some plant foods $[16,17,19$, 27]; hence, mushrooms could have high antioxidant activity. A mushroom phenolic compound has been found to be an excellent antioxidant and synergist that is not mutagenic [15]. 
Distribution of nutrients, polyphenols and antioxidant activities in the edible mushrooms 395

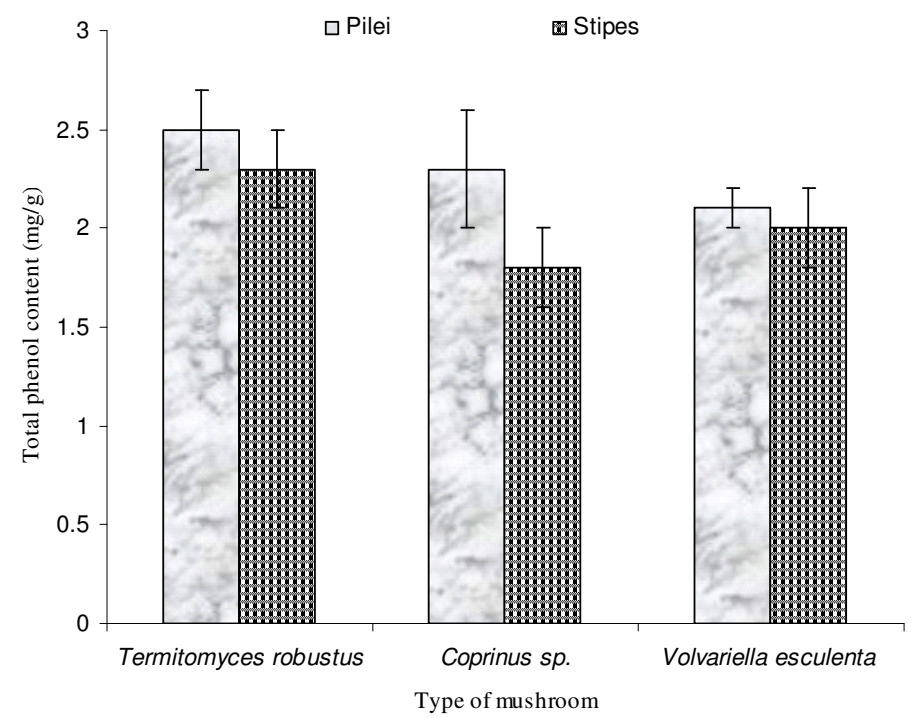

Figure 1. Distribution of polyphenols in some edible mushrooms $(n=3)$.

Phenols, including flavonoids, can potentially protect body cells against ('anti-') the damage caused by reactive oxygen species (ROS). Much of the total antioxidant activity of fruits and vegetables is related to their phenolic content, not only to their vitamin $\mathrm{C}$ content. Research reports have suggested that many polyphenol are more potent antioxidants than vitamins $\mathrm{C}$ and E [10, 11]. Moreover, Pietta et al. [28] had earlier reported that the phenolic compounds are responsible for most of the antioxidant activity in plants, while some studies have shown that the effective bioactive substance in mushrooms are mainly phenolic compounds with strong antioxidant activity [29]. Natural polyphenols exert their beneficial health effects by their antioxidant activity, these compounds are capable of removing free radicals, chelate metal catalysts, activate antioxidant enzymes, reduce $\alpha$-tocopherol radicals, and inhibit oxidases [3031]. In addition, to their role as antioxidant, some of them are known to have anti-inflammatory and anti-proliferative activities [29].

Reducing power can be a novel antioxidation defence mechanism; the two mechanisms that are available to affect this reducing power are by electron transfer and hydrogen atom transfer [32]. The reducing power of the extracts was assessed based on their ability to reduce Fe(III) to $\mathrm{Fe}(\mathrm{II})$ and the results are presented in Figure 2, which shows that the polyphenol extracts from the stipes had a significantly higher $(\mathrm{p}<0.05)$ reducing power than their corresponding pilei. However, the stipe of Volvariella esculenta had the highest reducing power, while the stipe of Termitomyces robustus had the least reducing power. Likewise the pilei of Volvariella esculenta had the highest reducing power, while the pilei of Termitomyces robustus had the least reducing power. It is worth noting that despite the fact that there was no significant difference $(p>0.05)$ in the phenol distribution between the stipes and pilei of the edible mushrooms, their stipes' extracts have higher reducing power. 


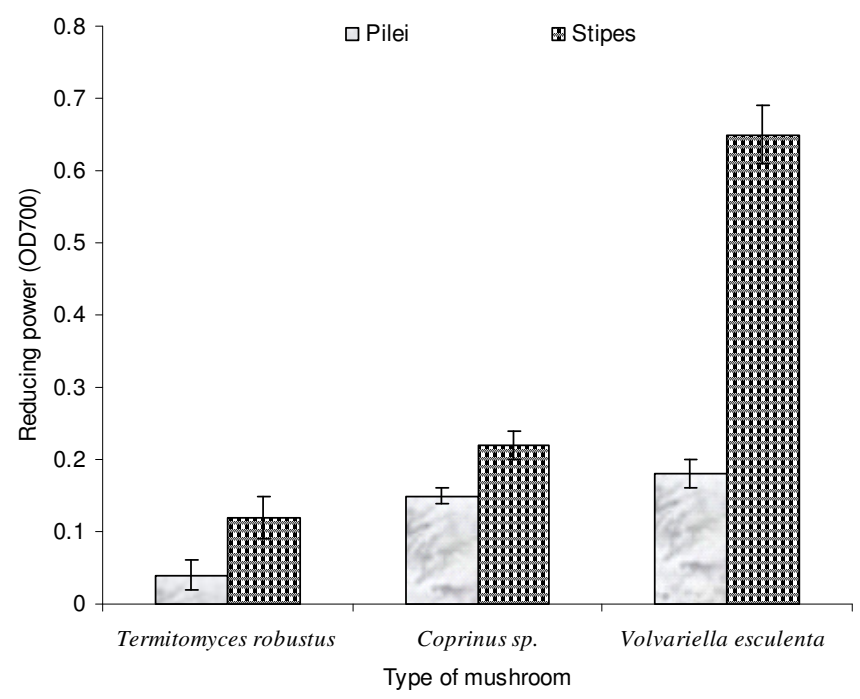

Figure 2. Reducing power polyphenol extracts from some edible mushrooms in Nigeria $(n=3)$.

The basis for the lack of agreement between phenolic distribution and reducing power of those mushrooms cannot be categorically stated, however it may not be far fetch from the fact that several hundreds of phenolic compounds with different structures exist in plants, therefore, structural difference of the phenolics in the mushroom extracts may have been responsible for the difference in their reducing property [33]. Therefore, the phenolic compounds in the stipes extract may have higher antioxidant activity, in that they have higher ability to reduce $\mathrm{Fe}(\mathrm{III})$ to $\mathrm{Fe}(\mathrm{II})$. The reducing capacity of a compound may serve as a significant indicator of its potential antioxidant activity. However, antioxidants activity has been attributed to various mechanisms, among which are prevention of chain initiation, binding of transition metal ion catalysts (metal chelation potential), decomposition of peroxides, and prevention of continued hydrogen abstraction, reductive capacity and radical scavenging [33].

The prevention of the chain initiation step by scavenging various reactive species such as free radicals is considered an important antioxidant mode of action [32]. The free radical scavenging ability of the polyphenol extracts are presented in Figure 3. The results revealed that the stipes had a significantly $(\mathrm{p}<0.05)$ higher free radical scavenging ability than their corresponding pilei. However, there was no agreement between the phenolic distribution in the mushrooms and DPPH free radical scavenging ability of the mushrooms. This result goes a long way in confirming the results obtained on reducing power in that antioxidant activity appears to concentrate more on the stipes of the mushrooms than the pilei of the mushrooms. Nevertheless, phenolic extracts from the stipes of Volvariella esculenta had the highest free radical scavenging ability, while the phenolic extract from the stipe of Coprinus sp. had the least free radical scavenging ability. Likewise, amongst the pilei, the polyphenol extract from Volvariella esculenta pilei had the highest free radical scavenging ability while that of Coprinus sp. had the least free radical scavenging ability. This lack of agreement between the total phenol content and the reducing power and free radical scavenging ability points to the possibility that there may be some non-phenolic compounds in the extracts such as vitamin C, vitamin E, amino acids, peptides and phytate $[11-13,16]$, that may have contributed to its reducing power and free radical scavenging ability. 
Distribution of nutrients, polyphenols and antioxidant activities in the edible mushrooms 397

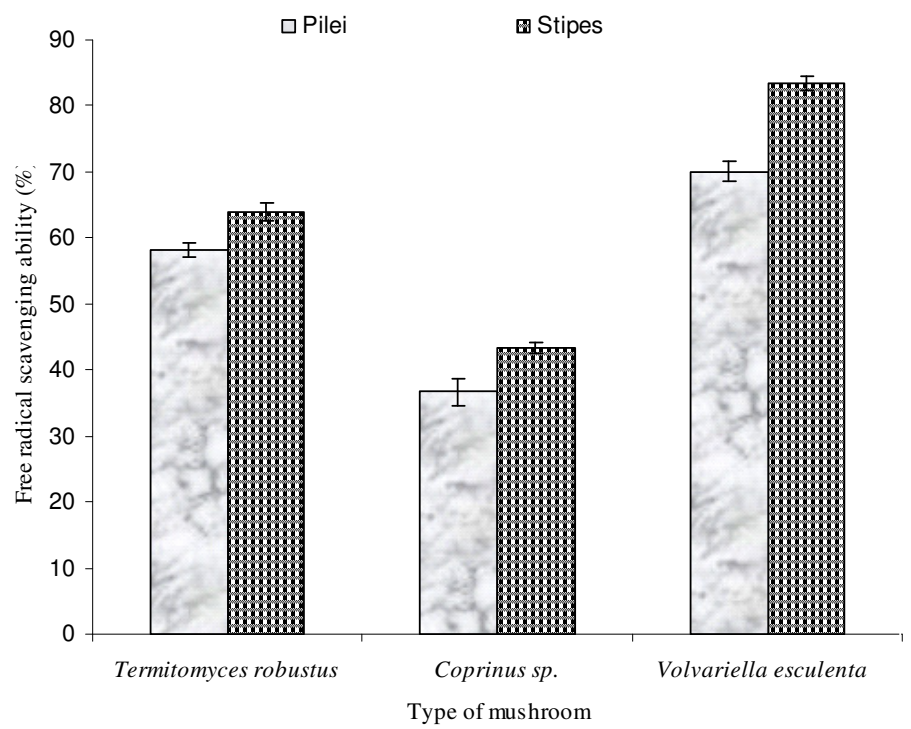

Figure 3. Free radical scavenging activity of polyphenol extracts from some edible mushrooms in Nigeria $(n=3)$.

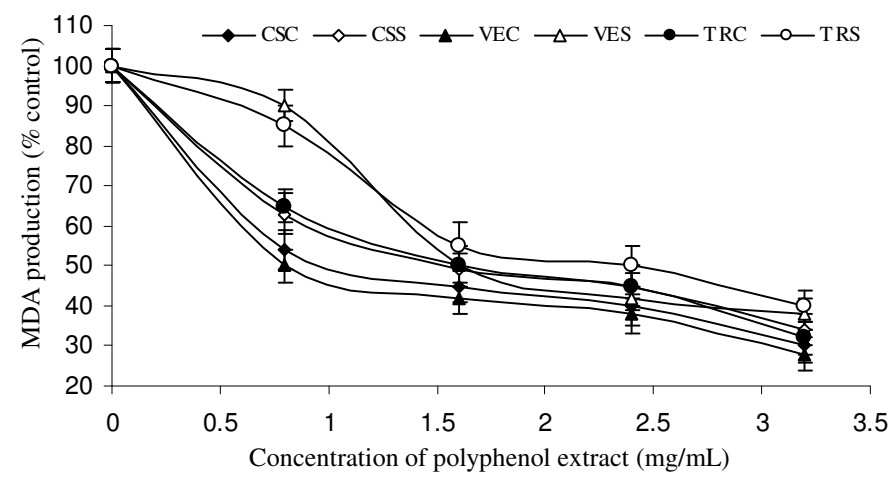

Figure 4. Inhibition of lipid peroxidation in cow's brain by polyphenol extracts from some edible mushrooms $(\mathrm{n}=3)$. CSC: Coprinus sp pilei, CSS: Coprinus sp stipes, VEC: Volvariella esculenta pilei, VES: Volvariella esculenta stipes, TRC: Termitomyces robustus pilei, TRS: Termitomyces robustus stipes.

Lipid peroxidation is thought to proceed via radical-mediated abstraction of hydrogen atoms from methylene carbons in polyunsaturated fatty acids [34]. Malondialdehyde (MDA) is one of the end products of lipid peroxidation and extent of lipid peroxidation is measured by estimation MDA levels. Figure 4 shows the inhibition of lipid peroxidation in cow's brain homogenates. The polyphenol extracts caused a marked decrease in the MDA content in the cow's brain (in vitro) in a dose-dependent manner. The decrease in the lipid peroxidation in these tissues homogenates in the presence of the extract could be as a result of the ability of the antioxidant phytochemicals in the extracts to scavenge free radicals in these tissues' homogenates. However, there was no significant difference $(p>0.05)$ in the inhibitory effect of the extract at

Bull. Chem. Soc. Ethiop. 2009, 23(3) 
higher concentrations; these findings agree with the phenolic distribution of the mushrooms. This agreement between the phenolic distribution and the inhibition of lipid peroxidation agrees with our earlier reports on pepper [35].

\section{CONCLUSIONS}

As a conclusion, the pilei of the mushrooms (Termitomyces robustus, Coprinus sp. and Volvariella esculenta) contained more protein, ash and fat content while there was no significant difference $(\mathrm{p}>0.05)$ in the polyphenol distribution between the pilei and stipes. However, the

polyphenol extracts from the stipes had significantly higher $(\mathrm{p}<0.05)$ antioxidant activity (except inhibition of lipid peroxidation) than those of the pilei.

\section{REFERENCES}

1. Fukushima, M.; Ohashi, T.; Fujiwara, Y.; Sonoyama, K. Exp. Biol. Med. 2001, 226, 758.

2. Huang, N.L. Edible Fungi of China 2002, 21, 7.

3. Kim, S.Y.; Kim, S.K.; Kim, J.H.; Oh, M.J.; Jung, M.Y. J. Am. Oil Chem. Soc. 1994, 71, 663.

4. Breene, W.M. J. Food Prot. 1990, 53, 883.

5. Gulcın, I.; Oktay, M.; Kırecc, E.; Kufrevioglu O.I. Food Chem. 2003, 83, 371.

6. Jiala, I.; Devaraj, S. Clin. Biochem. Persp. 1996, 42, 498.

7. Mak, Y.T.; Aruoma, O.I.; Spencer, J.P.E.; Rossi, R.; Aeschbach, R.; Khan, A.; Mahmood, N.; Munoz, A.; Murcia, A.; Butler, J.; Halliwell, B. Food Chem. Toxicol. 1996, 8, 449.

8. Pokorny, J. Trends Food Sci. Technol. 1991, 9, 223.

9. Block, G.; Patterson, B.; Subar, A. Nutr. \& Canc. 1992, 18, 1.

10. Oboh, G.; Akindahunsi, A.A. Nutr. Health 2004, 18, 29.

11. Oboh, G. Lebensm.-Wiss.u.-Technol. 2005, 38, 513.

12. Oboh, G. Eur. Food Res. Technol. 2006, 224, 61.

13. Oboh, G.; Puntel, R.L.; Rocha, J.B.T. Food Chem. 2007, 102, 178.

14. Barry, H. Biochem. Pharmacol. 1995, 49, 1341.

15. Ishikawa, Y.; Morimoto, K.; Hamaski, T. J. Am. Oil Chem. Soc.1984, 61, 1864.

16. Ola, F.L.; Oboh, G. J. Technosci. 2000, 4, 1.

17. Ola, F.L.; Oboh, G. Nahrung 2001, 45, 67.

18. Association of Official Analytical Chemists (AOAC) Official Methods of Analysis, 15th ed., Association of Official Analytical Chemists: Washington, D.C.; 1990.

19. Chu, Y.; Sun, J.; Wu, X.; Liu, R.H. J. Agric. Food Chem. 2002, 50, 6910.

20. Singleton, V.L.; Orthofer, R.; Lamuela-Raventos, R.M. Analysis of Total Phenols and Other Oxidation Substrates and Antioxidants by means of Folin-Ciocalteu Reagent, Methods inEnzymology, Vol. 299, (Oxidants and Antioxidants, Part A); Academic Press: San Diego, CA; 1999; pp 152-178.

21. Oyaizu, M. Jap. J. Nutr. 1986, 44, 307.

22. Gyamfi, M.A.; Yonamine, M.; Aniya, Y. Gen. Pharmacol. 1999, 32, 661.

23. Ohkawa, H.; Ohishi, N.; Yagi, K. Anal. Biochem. 1979, 95, 351.

24. Zar, J.H. Biostatistical Analysis, Prentice-Hall: USA; 1984; pp 620.

25. León-Guzmán, M.F.; Silva, I.; López, M.G. J. Agric. Food Chem. 1997, 45, 4329.

26. Adejumo, T.O.; Awosanya, O.B. Afr. J. Biotechnol. 2005, 4, 1084.

27. Sun, J.; Chu, Y.F.; Wu, X.; Liu, R.H. J. Agric. Food Chem. 2002, 50, 7449.

28. Pietta, P.; Simonetti, P.; Gardana, C.; Mauri, P. J. Pharm. Biomed. Anal. 2000, 23, 223.

29. Chao, G.R. Master's Thesis, Taiwanese National Chung Hsing University, China, 2001.

30. Alia, M.; Horcajo, C.; Bravo, L.; Goya, L. Nutr. Res. 2003, 23, 1251. 